\title{
Production of low impurity aluminium rotor for motor efficiency enhancement
}

\author{
Savitri Payakkapol ${ }^{1}$, Nattapon Chayopitak ${ }^{2},{\text { Panya } \mathrm{Kunsuwan}^{3}, \text { Naoto Ohtake }^{4} \text { and Sompong Srimanosaowapak }}^{5, *}$ \\ ${ }^{1}$ International College, King Mongkut's Institute of Technology Ladkrabang, Bangkok 10520, Thailand \\ ${ }^{2}$ National Electronics and Computer Technology Center (NECTEC), National Science and Technology Development Agency (NSTDA), \\ Klong Luang, Pathumthani 12120, Thailand \\ ${ }^{3}$ Faculty of Mechanical Engineering, King Mongkut's Institute of Technology Ladkrabang, Bangkok 10520, Thailand \\ ${ }^{4}$ Department of Mechanical Engineering, Tokyo Institute of Technology, Tokyo, Japan \\ ${ }^{5}$ National Metal and Materials Technology Center (MTEC), National Science and Technology Development Agency (NSTDA), Klong \\ Luang, Pathumthani 12120, Thailand
}

\begin{abstract}
Induction motors have been widely used in various electrical applications. However, their efficiency are still limited due to losses occurring during operation,especially for smaller ratings. Higher the electrical conductivity of motor rotor by lower its impurity content is one of practical and simple way to improve motor efficiency. The aim of this work is to reduce the impurity content of aluminium rotor by addition of boron in the form of $\mathrm{Al}-5 \mathrm{wt} \% \mathrm{~B}$ master alloy and $\mathrm{Na}_{2} \mathrm{~B}_{4} \mathrm{O}_{7}-\mathrm{NaCl}-\mathrm{KCl}$ flux, and then sedimention of their precipitated particles. The purer melt was then cast as rotors for single-phase induction motors. With the amount of addition of boron in aluminium melt in this work, boron in $\mathrm{Al}-5 \mathrm{wt} \% \mathrm{~B}$ master alloy was more pronounced in removing impurities in aluminium melt than that in $\mathrm{Na}_{2} \mathrm{~B}_{4} \mathrm{O}_{7}$. It was found that the rotors made of aluminium melt with lower impurity contents and hence higher electrical conductivity resulted in more enhancement of motor efficiency.
\end{abstract}

\section{Introduction}

Induction motors with aluminium squirrel-cage rotors have been widely used in various electrical applications. However, their efficiency are still limited due to losses associated with iron core, stray load, stator, rotor resistance, windage losses and friction, resulting in the low efficiency of around $70 \%$ for smaller rating [1-2]. Consequently, improvement of motor efficiency is a subject which has recently received increasing attention [3-4]. Practical and simple method to improve motor efficiency is to enhance conductivity of existing aluminium squirrel-cage rotor, by increasing purity of the aluminium used. In general, it is more economical to use lower grade aluminium in the production process and enhance its purity during melting and rotor casting process, rather than using higher aluminium grade. This work aims to increase the conductivity of aluminium rotor by precipitation and sedimentation method for $750 \mathrm{~W}$ shaded-pole induction motor used in small refrigeration applications.

The experimental procedures consist of two parts. First, the impurity removal methods in aluminium using Boron and $\mathrm{Na}_{2} \mathrm{~B}_{4} \mathrm{O}_{7}$ treatments were investigated for aluminium sample with $99.91 \mathrm{wt} \%$ in laboratory setup. Second, the more convenient method is then chosen to prototype the rotor of induction motor for efficiency test with industrial grade alunimium with $99.85 \mathrm{wt} \%$ in real manufacturing production setup.

\section{Experimental Procedures}

\subsection{Impurity removal methods using Boron and $\mathrm{Na}_{2} \mathrm{~B}_{4} \mathrm{O}_{7}$ treatments}

Aluminium sample with $99.91 \mathrm{wt} \%$ purity, whose main chemical compositions measured using optical emission spectroscopy (OES) are given in Table 1, was used as a material to remove its impurity using $\mathrm{Al}-5 \mathrm{wt} \% \mathrm{~B}$ (Boron) and $\mathrm{Na}_{2} \mathrm{~B}_{4} \mathrm{O}_{7}$ addition. Al-5wt\%B master alloy in the form of rod produced by AMG Aluminum was used. The amount of B required for chromium, titanium, vanadium and zirconium removal as insoluble borides is determined using the below stoichiometric equation.

$$
B=\left(\frac{M}{P}\right) * \frac{C r+T i+V+Z r}{2}
$$

where $\mathrm{B}$ is the total weight of the Al-B master alloy required $(\mathrm{kg}), \mathrm{Cr}, \mathrm{Ti}, \mathrm{V}, \mathrm{Zr}$ are the concentration of impurity elements (wt \%), $\mathrm{M}$ is the weight of aluminium to be treated $(\mathrm{kg})$, and $\mathrm{P}$ is the concentration of $\mathrm{B}$ in $\mathrm{Al}-$ $\mathrm{B}$ master alloy (wt.\%) [5]. For the impurity removal using $\mathrm{Na}_{2} \mathrm{~B}_{4} \mathrm{O}_{7}$ addition, $0.9 \mathrm{wt} \% \mathrm{Na}_{2} \mathrm{~B}_{4} \mathrm{O}_{7}$, which gave high iron removal in commercial purity aluminium [6],

\footnotetext{
* Corresponding author: sompongs@mtec.or.th
} 
Table 1. Chemical compositions of aluminium sample with $99.91 \mathrm{wt} \%$ purity used in laboratory setup (wt\%).

\begin{tabular}{|c|c|c|c|c|c|c|}
\hline $\mathbf{F e}$ & $\mathbf{S i}$ & $\mathbf{Z n}$ & $\mathbf{T i}$ & $\mathbf{V}$ & $\mathbf{C r}$ & $\mathbf{A l}$ \\
\hline 0.055 & 0.01 & 0.001 & 0.003 & 0.012 & 0.001 & 99.91 \\
\hline
\end{tabular}

Table 2. Weight ratio of $\mathrm{Na}_{2} \mathrm{~B}_{4} \mathrm{O}_{7}-\mathrm{NaCl}-\mathrm{KCl}$ flux.

\begin{tabular}{|c|c|c|}
\hline $\mathbf{N a C l}$ & $\mathbf{K C l}$ & $\mathbf{N a}_{2} \mathbf{B}_{4} \mathbf{O}_{7}$ \\
\hline 10 & 10 & 9 \\
\hline
\end{tabular}

Table 3. Chemical compositions of industrial grade aluminium $99.85 \mathrm{wt} \%$ purity used for rotor prototype in manufacturing production (wt $\%)$.

\begin{tabular}{|c|c|c|c|c|c|c|}
\hline $\mathbf{F e}$ & $\mathbf{S i}$ & $\mathbf{Z n}$ & $\mathbf{T i}$ & $\mathbf{V}$ & $\mathbf{Z r}$ & $\mathbf{A l}$ \\
\hline 0.076 & 0.036 & 0.002 & 0.002 & 0.017 & 0.001 & 99.85 \\
\hline
\end{tabular}

was added to aluminium melt in the form of flux having been mixed with $\mathrm{NaCl}$ and $\mathrm{KCl}$ using a ball mill with the ratio given in Table 2 .

Al-5wt $\% \mathrm{~B}$ master alloy and $\mathrm{Na}_{2} \mathrm{~B}_{4} \mathrm{O}_{7}-\mathrm{NaCl}-\mathrm{KCl}$ flux were each vigorously stirred for 1 minute after addition in each approximately $3 \mathrm{~kg}$ aluminium melt at $720 \pm$ $2{ }^{\circ} \mathrm{C}$. Each melt including the one without any addition was held for $15 \mathrm{hrs}$ to precipitate and sediment of boride and other particles. The melt was sampled for chemical analysis prior to boron addition and at intervals during the holding period. At the end of the experiments, each remaining melt was left to cool inside the furnace, after which the observation of boride particles at the bottom of the remaining metal was performed using Hitachi SU 5000 scanning electron microscopy with energy dispersive spectroscopy (EDS) system.

\subsection{Aluminium rotor prototype using Boron treatment}

Industrial grade aluminium with $99.85 \mathrm{wt} \%$ purity, which was boron treated using $\mathrm{Al}-5 \mathrm{wt} \% \mathrm{~B}$ master alloy, was used for rotor production at $720 \pm 2{ }^{\circ} \mathrm{C}$ using a 350 ton high pressure die casting machine. Chemical compositions of the aluminium prior to impurity removal are given in Table 3. After degassing and 9.5g Al$5 \mathrm{wt} \% \mathrm{~B}$ master alloy addition, melt was sampled for chemical analysis and taken for rotor casting each of about $0.38 \mathrm{~kg}$ at 5 -minute intervals up to $1 \mathrm{hr}$. Biscuit and runner of each produced rotor casting were then sectioned and measured their porosity using Archimedes method [7]. Selected rotor castings having low porosities of their biscuit and runner were machined and assembled with a single phase shaded-pole induction motor rating $750 \mathrm{~W}, 1,300 \mathrm{rpm}, 220 \mathrm{~V} \mathrm{AC}$, as shown for example in Figure 1. Efficiency of motors was then tested using a MAGTROL Hysteresis dynamometer at the speed of $1,300 \mathrm{rpm}$.

\section{Results and discussion}

\subsection{Impurity removal using Boron and $\mathrm{Na}_{2} \mathrm{~B}_{4} \mathrm{O}_{7}$ treatments}

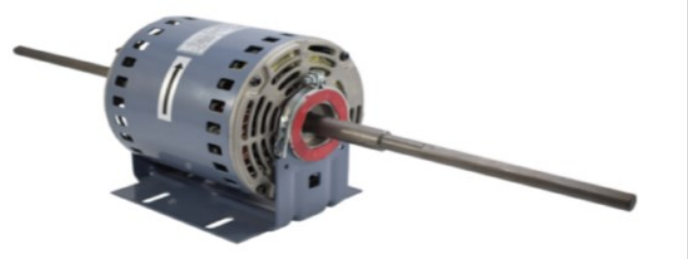

Fig 1. A prototype of the single phase shaded-pole induction motor rating $750 \mathrm{~W}, 1,300 \mathrm{rpm}, 220 \mathrm{~V} \mathrm{AC}$.

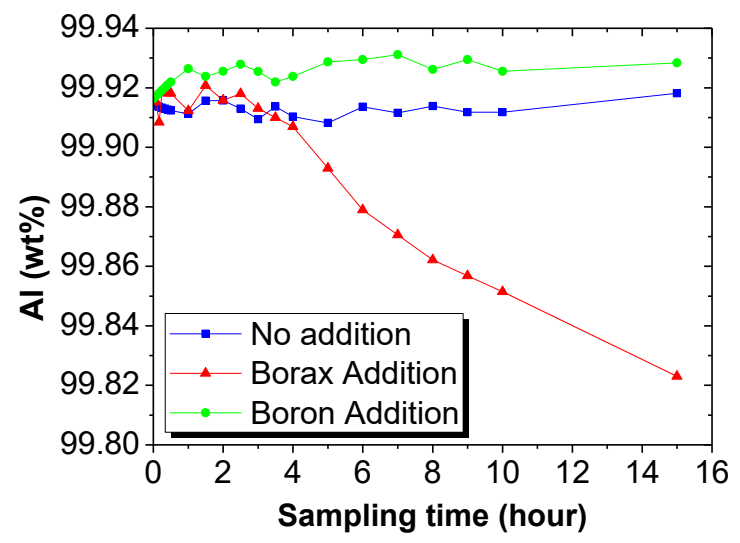

Fig. 2. Al content in $99.91 \mathrm{wt} \%$ purity $\mathrm{Al}$ melts which had experienced different purification processes and holding times.

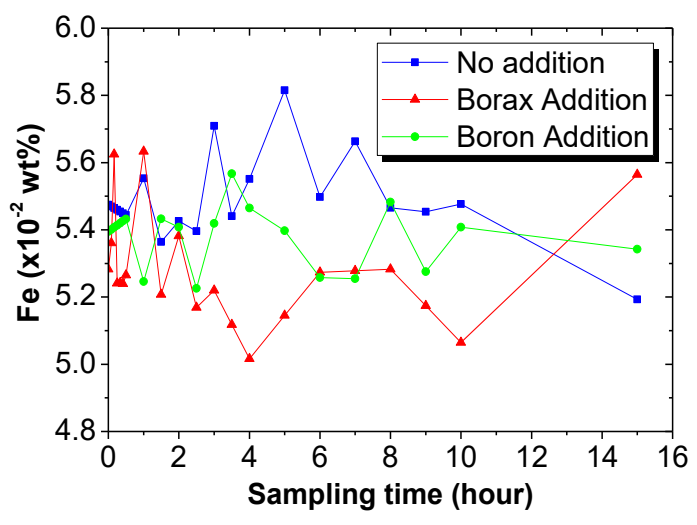

Fig. 3. Fe content in $99.91 \mathrm{wt} \%$ purity $\mathrm{Al}$ melts which had experienced different purification processes and holding times.

In laboratory setup, after holding the melts with Al$5 \mathrm{wt} \% \mathrm{~B}$ master alloy addition, $\mathrm{Na}_{2} \mathrm{~B}_{4} \mathrm{O}_{7}-\mathrm{NaCl}-\mathrm{KCl}$ flux addition and without any addition for $15 \mathrm{hrs}$, the chemical compositions of the melts, except for the one without addition, changed from their initial values, where the results are shown in Figures 2 - 5. The melts were found to be purer after the addition of $\mathrm{Al}-5 \mathrm{wt} \% \mathrm{~B}$ master alloy and $\mathrm{Na}_{2} \mathrm{~B}_{4} \mathrm{O}_{7}-\mathrm{NaCl}-\mathrm{KCl}$ flux during the whole and only initial period of holding, respectively, as shown in Figure 2. It should be noted that the addition of $\mathrm{Al}-5 \mathrm{wt} \% \mathrm{~B}$ master alloy results in purer melt than the addition of $\mathrm{Na}_{2} \mathrm{~B}_{4} \mathrm{O}_{7}-\mathrm{NaCl}-\mathrm{KCl}$ flux. However, Fe content in the melt with $\mathrm{Na}_{2} \mathrm{~B}_{4} \mathrm{O}_{7}-\mathrm{NaCl}-\mathrm{KCl}$ flux addition decreased more noticeably than the melt with $\mathrm{Al}-5 \mathrm{wt} \% \mathrm{~B}$ master alloy addition, as shown in Figure 3. $\mathrm{Al}-5 \mathrm{wt} \% \mathrm{~B}$ master alloy addition, on the other hands, was 
more effective in removing $\mathrm{V}$ and Ti than $\mathrm{Na}_{2} \mathrm{~B}_{4} \mathrm{O}_{7}$ $\mathrm{NaCl}-\mathrm{KCl}$ flux addition, as shown in Figures 4 and 5.

Samples of the sedimented layer in the melts after the precipitation-sedimentation process showed the presence of particles. Figure 6 shows, for example, the backscattered electron image of sedimented layer in the melt with $\mathrm{Al}-5 \mathrm{wt} \% \mathrm{~B}$ master alloy addition after precipitation and holding at $720^{\circ} \mathrm{C}$ for $15 \mathrm{hrs}$. Most particles are borides and the majority of them contained $\mathrm{V}$ and $\mathrm{Ti}$, which were identified as $(\mathrm{V}, \mathrm{Ti}) \mathrm{B}_{2}$. Evidence and discussion of transition metal borides precipitating after boron additions in aluminium melts have been reported $[6,8-10]$. This suggests that transition metal borides are stable in molten aluminium which paves the way for simple and practical removal of transition metal impurities and hence enhancement of electrical conductivity in aluminium.

\subsection{Aluminium rotor prototype using Boron treatment}

In manufacturing production setup, only the Boron treatment with $\mathrm{Al}-5 \mathrm{wt} \% \mathrm{~B}$ master alloy is chosen for effectiveness and practicality because it can reduce Ti, $\mathrm{V}$ and $\mathrm{Zr}$, whereas the application of $\mathrm{Na}_{2} \mathrm{~B}_{4} \mathrm{O}_{7}-\mathrm{NaCl}-\mathrm{KCl}$ flux can only reduce $\mathrm{Fe}$ significantly. Also it is more convenient in existing manufacturing procedure with simple addition of $\mathrm{Al}-5 \mathrm{wt} \% \mathrm{~B}$ master alloy in the melt, whereas the application of $\mathrm{Na}_{2} \mathrm{~B}_{4} \mathrm{O}_{7}-\mathrm{NaCl}-\mathrm{KCl}$ flux requires more steps in preparation. The $99.85 \mathrm{wt} \%$ purity aluminium melt after the Al-5wt\%B master alloy addition was sampled for chemical analysis and taken for rotor casting every 5-minute intervals. According to the chemical analysis result of the samples, it was found that the content of $\mathrm{V}, \mathrm{Ti}$ and $\mathrm{Zr}$ decreased with increasing holding time as shown in Figure 7(a), whereas $\mathrm{Fe}$ and $\mathrm{Si}$ remained unchanged as shown in Figure 7(b). Figure 8 shows an example of aluminium rotor casting. Biscuit and runner of each rotor castings were taken for porosity measurement, whose result is shown in Figure 9. It can be noted from this figure that the majority of biscuits and runners contained porosity less than $0.75 \%$. However, some castings contained higher porosities which may occur from the poor handling or pouring of the melt, which were carried out manually. Only the rotors produced from the reasonably low porosities of biscuits and runners were therefore used for prototyping $750 \mathrm{~W}$ single phase induction motors. Efficiency of the motors having the selected low porosity rotors is shown in Figure 10. It can be seen from this figure that, for the samples considered, the motor efficiency increased as the holding time of melt increased, although more test data are needed to establish a more defined trend. The enhance of motor efficiency with increasing holding time seems to be associated with a decrease in impurity quantity to a greater or lesser extent. Based on the relation of resistivity on impurity contents given in [11], the resistivity of aluminium rotors, which were taken to make-up the motors, in this work is estimated to be $3.151,3.149,3.139,3.145,3.132 \mu \Omega . c m$ for the rotors

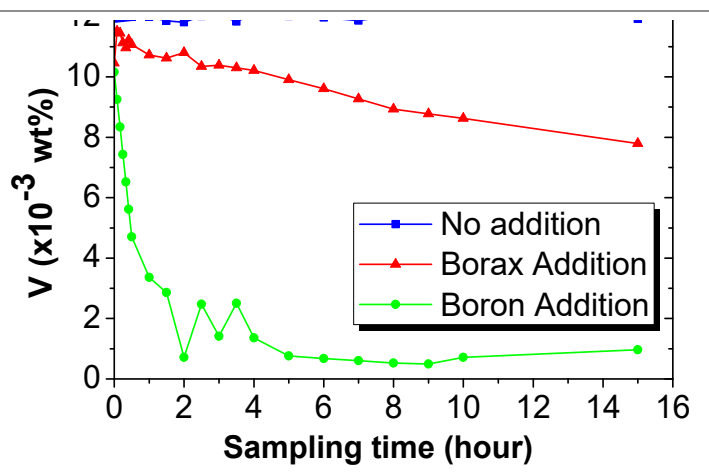

Fig. 4. $\mathrm{V}$ content in $99.91 \mathrm{wt} \%$ purity $\mathrm{Al}$ melts which had experienced different purification processes and holding times

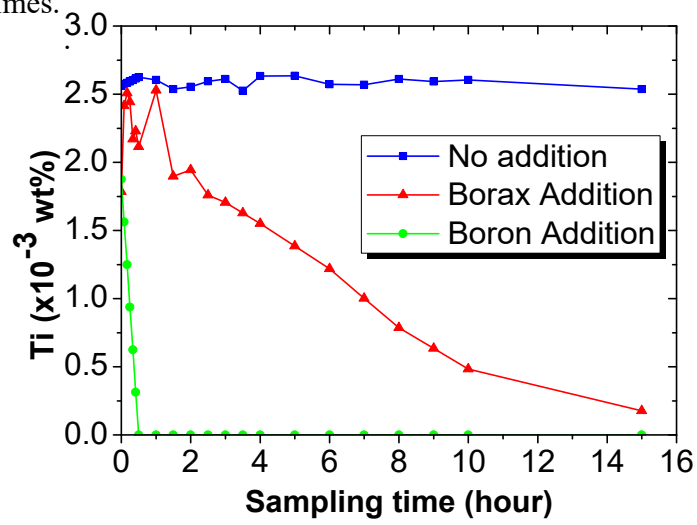

Fig. 5. Ti content in $99.91 \mathrm{wt} \%$ purity $\mathrm{Al}$ melts which had experienced different purification processes and holding

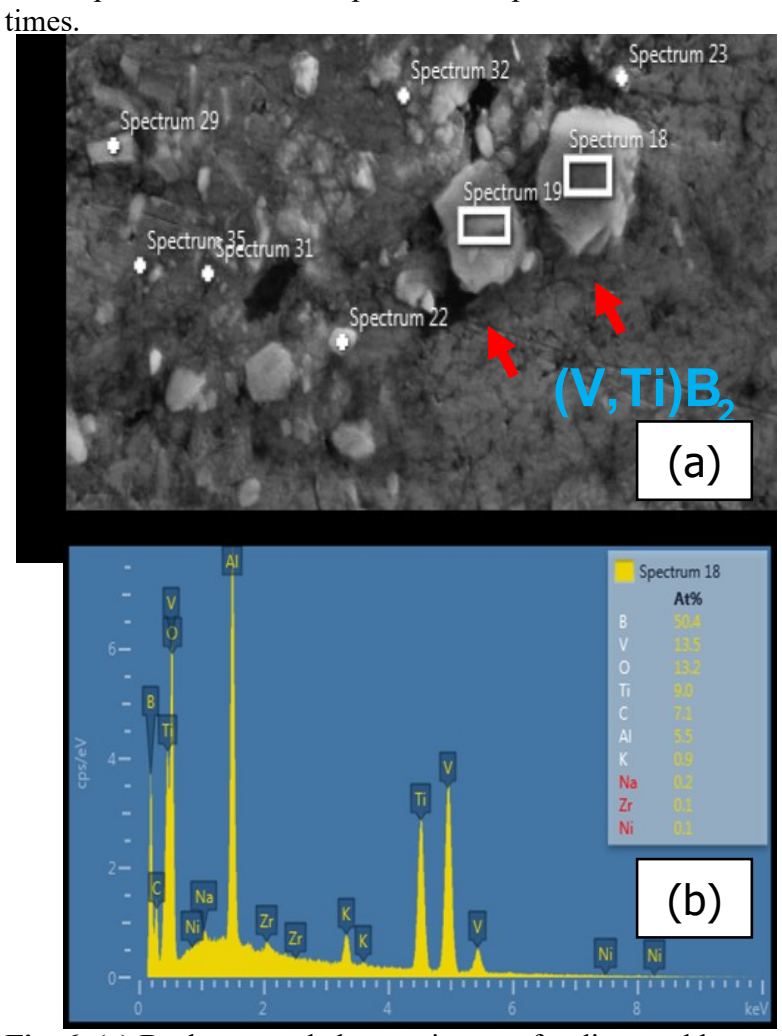

Fig. 6. (a) Backscattered electron image of sedimented layer and (b) chemical spectrum showing the presence of borides. holding time after the Al-5wt\% B master alloy addition. Hence, with the increase of aluminium purity, resulting in decreasing resistivity of aluminium casting in the rotor, this procedure helps reduceing the power losses in the rotor that eventually improves the overall efficiency of the motor. 

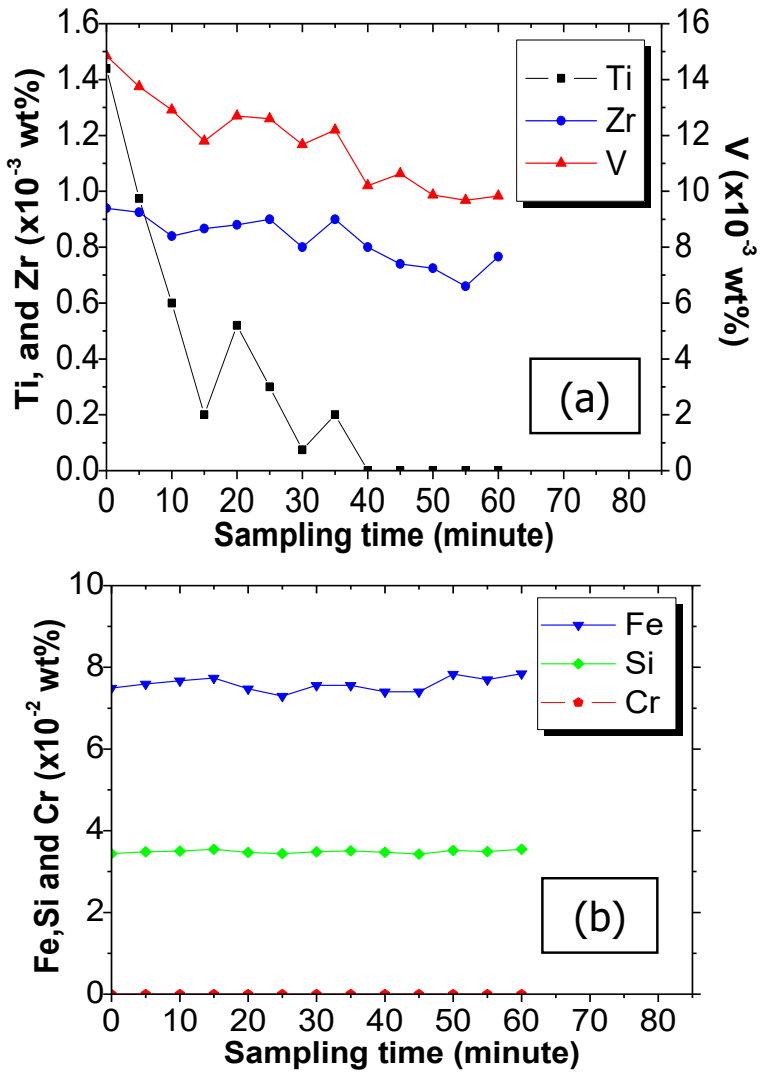

Fig. 7. Content of main impurities: (a) Ti, Zr, $\mathrm{V}$ and (b) Fe, Si, $\mathrm{Cr}$, in $99.85 \mathrm{wt} \%$ purity $\mathrm{Al}$ with $\mathrm{Al}-5 \mathrm{wt} \% \mathrm{~B}$ master alloy held for sedimentation at different times.

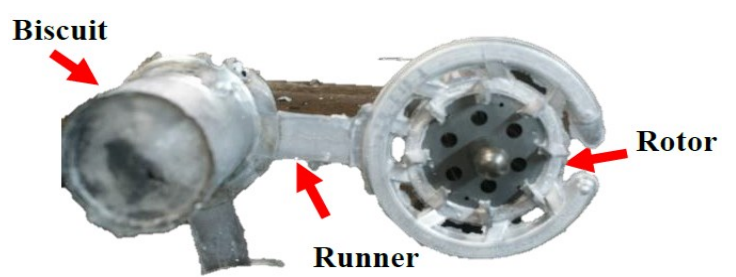

Fig. 8. Example of an aluminium rotor casting.

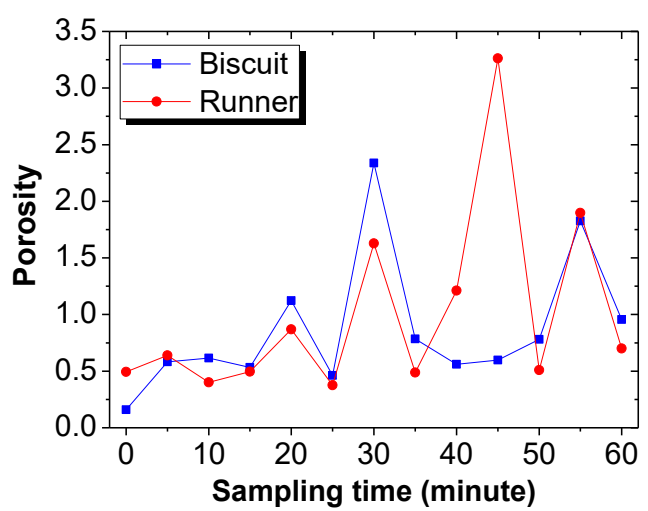

Fig. 9. Porosity of biscuit and runner of aluminium rotor castin

\section{Conclusions}

The precipitation and sedimentation of borides of transition metals in aluminium melt after addition of Al$5 \mathrm{wt} \% \mathrm{~B}$ master alloy and $\mathrm{Na}_{2} \mathrm{~B}_{4} \mathrm{O}_{7}-\mathrm{NaCl}-\mathrm{KCl}$ flux resulted in purer aluminium melt. With the amount of addition of boron in aluminium melt in this work, boron in $\mathrm{Al}-5 \mathrm{wt} \% \mathrm{~B}$ master alloy was more pronounced in removing impurities in aluminium melt than that in

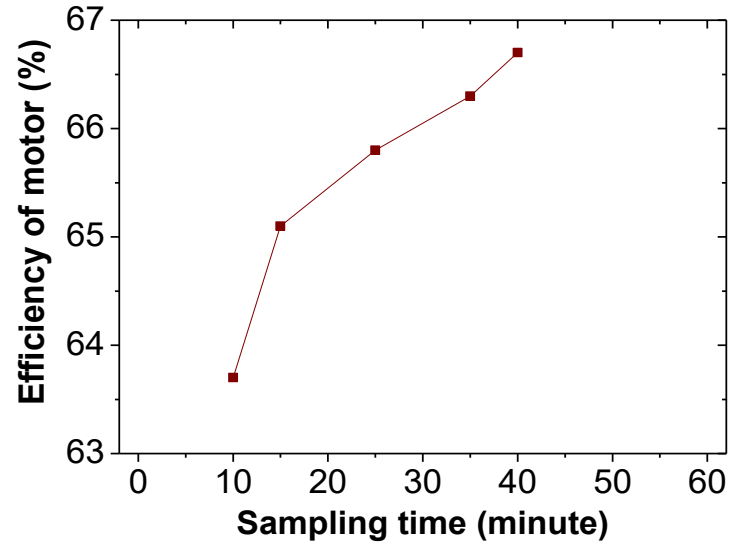

Fig. 10. Efficiency of single phase induction motors $(750 \mathrm{~W}$ and $1,300 \mathrm{rpm}$ ) having rotors made of aluminium melt with Al$5 \mathrm{wt} \% \mathrm{~B}$ master alloy held for sedimentation at different times.

$\mathrm{Na}_{2} \mathrm{~B}_{4} \mathrm{O}_{7}$. Although the addition of $\mathrm{Na}_{2} \mathrm{~B}_{4} \mathrm{O}_{7}-\mathrm{NaCl}-\mathrm{KCl}$ flux can reduce $\mathrm{Fe}$ significantly, the addition of Al$5 \mathrm{wt} \% \mathrm{~B}$ master alloy can reduce $\mathrm{Ti}, \mathrm{V}$ and $\mathrm{Zr}$. It was found that the rotors made of aluminium melt of industrial grade aluminium with lower impurity contents resulted in more enhancement of motor efficiency. It is expected that the motor efficiency can be improved further with the increase of the holding time of melt of the proposed method. The possible future work is to find the practical methods for transitioning more impurity metal to improve the efficiency of the motor.

The authors would like to express the appreciation to Kulthorn Electric Co.,Ltd Company for supplying materials and supporting with rotor casting production of motor prototypes and efficiency test.

\section{References}

1. Technical note: IEC 60034-30-1 standard on efficiency classes for low volttage AC motors, $\mathrm{ABB}$, $1-2$ (2014)

2. R. Tiwari, A.K. Bhardwaj, Inter. J. Innov. Res. Elec. Electron. Instr. Contr. Eng., 2, 1552-1558 (2014)

3. S. Bauer, W. Braun, P. Orban, K. Schleede, P. Smith, Cs. Walczer, J. Mach. Manuf., XLIX, 82-83 (2009)

4. H. Su, H. Wen, X. Zheng, J. Su, Procedia Eng., 174, 1221-1228 (2017)

5. S. Karabay, I. Uzman, J. Mater. Process. Tech., 160, 174-182 (2005)

6. J. W. Gao, D. Shu, J. Wang, B.D. Sun, Mater. Sci. Technol., 25, 619-624 (2009)

7. V.D. Tsoukalas, Mater. Des., 29, 2027-2033 (2008)

8. P. Cooper, M. Kearns, Alminium Alloys: Their Physical and Mechanical Properties, Pts 1-3, 217, 141-146 (1996)

9. A. Khaliq, M.A. Rhamdhani, G.A. Brooks, J. Grandfield, Metall. Mater. Trans. B, 45, 784-794 (2014)

10. T.X. Ping, ZK. Hong, S.D. Fu, Z.X. Ming, Chinese J. Nonferrous Met., 24, 1401-1407 (2014)

11. W.A. Dean, Aluminium, 1, 174 (1967) 